\title{
Chemical analysis of gem-grade cordierite from Canada
}

\author{
FOX, K.E. ${ }^{1 *}$, YAKYMCHUK, C. ${ }^{2}$
}

Earth and Environmental Science, University of Waterloo,

Ontario, Canada

${ }^{1}$ (* correspondence: kefox.ca@gmail.com)

2 (cyakymchuk@uwaterloo.ca)

Cordierite is a globally distributed rock-forming mineral of nominal formula $(\mathrm{Mg}, \mathrm{Fe})_{2} \mathrm{Al}_{4} \mathrm{Si}_{5} \mathrm{O}_{18} \cdot\left(\mathrm{H}_{2} \mathrm{O}, \mathrm{CO}_{2}\right)$. It is important not just as an indicator of metamorphic grade, but also as the blue gemstone "iolite". Although cordierite has been extensively studied, the specimens were rarely of gem grade, and data was generally insufficient to identify trace element signatures that might be unique to certain localities.

In the current work, the elemental composition of gem- or near gem-grade cordierite from 15 localities across Canada has been studied using electron microprobe analysis for major/minor elements and laser ablation-inductively coupled plasma-mass spectrometry (LA-ICP-MS) for trace elements. Many of the sites which sourced these specimens are or were active mining localities, or were discovered during exploration activity. All are associated with metamorphic environments.

Results show that molar ratios of $\mathrm{Fe} /[\mathrm{Fe}+\mathrm{Mg}+\mathrm{Mn}]$ vary between 0.15 and 0.4 across different localities. Concentrations of $\mathrm{Na}$ are $<3300 \mathrm{ppm}, \mathrm{Li}<400 \mathrm{ppm}$ and $\mathrm{Be}$ $<70 \mathrm{ppm}$, all on the low end of the reported range for cordierite, while trace amounts of $\mathrm{Zn}, \mathrm{Ga}, \mathrm{Ni}, \mathrm{Co}, \mathrm{Rb}$ and $\mathrm{Cs}$ were also measured. As shown in Figure 1, the Geco $\mathrm{Cu}-\mathrm{Zn}$ mine in Ontario shows elevated levels of $\mathrm{Zn}$ relative to other sites, while the metapelites on the south coast of Baffin Island are richer in $\mathrm{Cs}, \mathrm{Rb}$, Ni and Co with relatively little $\mathrm{Li}$ or $\mathrm{Zn}$. This and alternative visualizations of the data from this study show that in many cases distinctions between localities are possible based on the concentration of elements taken into the cordierite lattice.

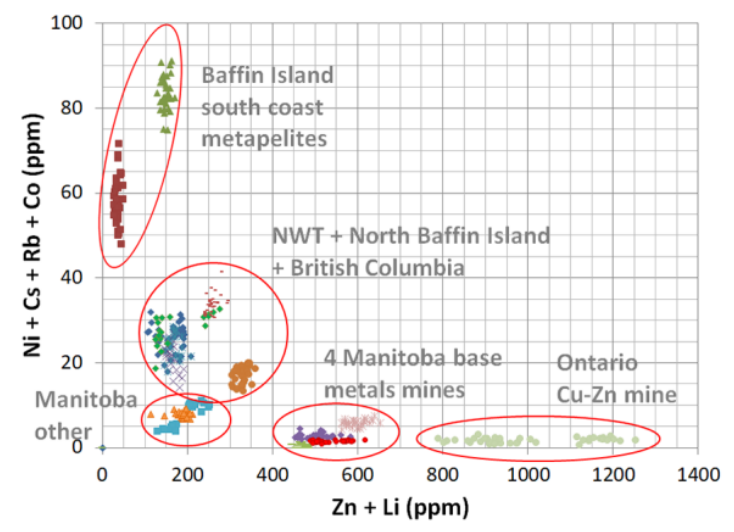

Figure 1. A locality discrimination plot for cordierite from 15 localities in Canada. 